\title{
Incidence and Risk Factors of Bisphosphonate- Related Osteonecrosis of the Jaw in Multiple Myeloma Patients Having Undergone Autologous Stem Cell Transplantation
}

\author{
Cornelia Then $^{\mathrm{a} *}$ Natalie Hörauf ${ }^{\mathrm{b} *}$ Sven Otto $^{c}$ Christoph Pautke $^{c}$ Emmo von Tresckow ${ }^{d}$ \\ Tim Röhnisch $^{\mathrm{b}}$ Philipp Baumann ${ }^{\mathrm{b}}$ Ralf Schmidmaier ${ }^{\mathrm{b}} \quad$ Irmgard Bumeder $^{\mathrm{b}} \quad$ Fuat S. Oduncu $^{\mathrm{b}}$ \\ aDivision of Endocrinology and Diabetology, \\ ${ }^{b}$ Division of Hematology and Oncology, Medizinische Klinik und Poliklinik IV, Klinikum der Universität München, \\ 'Department of Oral and Maxillofacial Surgery, Ludwig-Maximilians University Munich, 'Starnberg, Germany
}

\section{Keywords}

Multiple myeloma - Autologous stem cell transplantation . Bisphosphonate-related osteonecrosis of the jaw . BRONJ $\cdot$ ONJ

\section{Summary}

Background: Bisphosphonate-related osteonecrosis of the jaw (BRONJ) is a severe complication of bisphosphonate therapy. Due to their long survival and subsequently high cumulative doses of bisphosphonates, multiple myeloma patients have the highest risk of developing BRONJ of all patients treated with bisphosphonates. The purpose of the present study was to evaluate the incidence and risk factors for BRONJ in multiple myeloma patients after high-dose chemotherapy and autologous stem cell transplantation (ASCT). Patients and Methods: We retrospectively analyzed the data of 120 multiple myeloma patients after high-dose chemotherapy and ASCT treated with bisphosphonates and assessed the incidence and risk factors of BRONJ. Results: Of the 120 patients, 23 (19\%) developed BRONJ. 6 patients suffered several BRONJ events, resulting in a total incidence of $23 \%$. The risk for BRONJ was significantly higher for patients with rheumatism and recent dental manipulations. Furthermore, the number of previous bisphosphonate rotations, the duration of bisphosphonate therapy, and the type and cumulative dose of bisphosphonate used were associated with the incidence of BRONJ. Conclusion: Our study is the first to determine the risk of BRONJ in a homogeneous group of multiple myeloma patients treated with high-dose chemotherapy and ASCT.

\section{Schlüsselwörter}

Multiples Myelom - Autologe Stammzelltransplantation . Bisphosphonat-assoziierte Kieferosteonekrose - BRONJ . ONJ

\section{Zusammenfassung}

Hintergrund: Bisphosphonat-assoziierte Kiefernekrosen (BRONJ) sind eine schwere Nebenwirkung der Bisphosphonattherapie. Aufgrund ihres langen Überlebens mit den daraus resultierenden hohen kumulativen Bisphosphonatdosen haben Myelompatienten im Vergleich mit anderen Patienten unter Bisphosphonattherapie das höchste Risiko für BRONJ. Ziel der Studie war es, Inzidenz und Risikofaktoren für BRONJ bei Myelompatienten zu untersuchen, die zuvor eine Hochdosischemotherapie und autologe Stammzelltransplantation (ASCT) erhalten hatten. Patienten und Methoden: Die Daten von 120 Myelompatienten unter Bisphosphonattherapie nach Hochdosischemotherapie und ASCT wurden analysiert. Ergebnisse: Von den 120 Patienten entwickelten 23 (19\%) BRONJ. 6 Patienten erlitten mehr als ein BRONJ-Ereignis, was eine Gesamtinzidenz von 23\% ergab. Das BRONJ-Risiko war für Patienten mit einer rheumatischen Erkrankung oder einer kürzlich erfolgten Zahnmanipulation erhöht. Zudem waren die Zahl der BisphosphonatPräparatwechsel, die Therapiedauer, die Art und die kumulative Bisphosphonatdosis mit dem BRONJ-Risiko assoziiert. Schlussfolgerung: Dies ist die erste Studie, die das BRONJ-Risiko in einer homogenen Patientengruppe mit multiplem Myelom nach Hochdosischemotherapie und ASCT untersucht.

*These two authors contributed equally to this study.

\section{KARGER}

Fax +497614520714

Information@Karger.de

www.karger.com (c) 2012 S. Karger GmbH, Freiburg

0378-584X/12/3511-0658\$38.00/0

Accessible online at:

www.karger.com/onk
PD Dr. Dr. Fuat S. Oduncu, MA, EMB, MBA

Division of Hematology and Oncology

Medizinische Klinik und Poliklinik IV, Klinikum der Universität München

Ziemssenstraße 1, 80336 Munich, Germany

fuat.oduncu@med.uni-muenchen.de 


\section{Introduction}

Osteolytic metastases are primarily caused by excessive bone resorption through osteoclasts with concurrently impaired osteoblast function. This is due to a variety of cytokines produced by metastatic cancer cells that can influence both osteoclast and osteoblast function [1]. A remedy to alleviate the effects of excessive bone resorption is treatment with bisphosphonates. Bisphosphonates are synthetic pyrophosphate ana$\operatorname{logs}$ that generate cytotoxic effects on different cells, and in particular on osteoclasts because they accumulate in this cell type, interfere with various pathways and subsequently reduce osteoclast activity, adhesion and migration ability and induce apoptosis and/or necrosis [2-5]. According to their chemical structure, bisphosphonates are subdivided into 4 groups: bisphosphonates without nitrogen substitution (e.g. etidronate, clodronate), aminobisphosphonates (e.g. pamidronate, alendronate), aminobisphosphonates with substitution of the nitrogen atom (e.g. ibandronate), and bisphosphonates with basic heterocycles containing nitrogen (e.g. zoledronic acid). The introduction of the nitrogen position increased the antiresorptive potency. The molecular mechanisms of action vary between different bisphosphonates: Bisphosphonates without nitrogen form a toxic ATP analog that inhibits the mevalonate pathway. Nitrogen-containing bisphosphonates inhibit multiple cellular pathways related to integrin signaling and apoptosis and also the mevalonic acid metabolic pathway and the prenylation of small GTPase signaling proteins [6].

Beside their beneficial effects on pain and reduction of fractures [7], bisphosphonates may also display antimyeloma and antitumor activity [8-11]. Event-free and overall survival are both improved in patients treated with bisphosphonates, which has particularly been shown for the nitrogen-containing bisphosphonate zoledronic acid [12, 13]. Thus, bisphosphonates have become an important component of the supportive care of patients with multiple myeloma or solid tumors with bone metastases. Adverse effects are infrequent and are primarily constituted by acute-phase reactions, complications of the upper aerodigestive tract such as esophageal ulceration, hypocalcemia, and impaired renal function [14]. However, first described in 2003, bisphosphonate-related osteonecrosis of the jaw (BRONJ) has emerged as a severe complication of bisphosphonate therapy [15-17]. BRONJ is defined by an area of exposed bone in the mandible or maxilla over a period exceeding 8 weeks, in patients with current or previous bisphosphonate intake and without history of irradiation of the jaw bone $[18,19]$. The exposed bone may be asymptomatic or associated with pain, infection, or further complications such as nerve impairment or pathological fractures. BRONJ predominantly affects patients receiving intravenous administrations of nitrogen-containing bisphosphonates due to malignant underlying diseases. The estimate of the cumulative incidence of BRONJ in these patients ranges from 0.8 to $20.5 \%$ $[20,21]$, but the highest incidence was found in patients with breast cancer and multiple myeloma [15, 22-26]. In the present study, we examined the incidence and risk factors of BRONJ in 120 multiple myeloma patients after high-dose chemotherapy and autologous stem cell transplantation (ASCT).

\section{Patients and Methods}

Patients and Determination of BRONJ

We retrospectively analyzed the data of 120 patients with multiple myeloma undergoing high-dose chemotherapy and ASCT from 2003 until 2008. The patients received melphalan at a dose between 140 and $200 \mathrm{mg} / \mathrm{m}^{2}$. Reinfusion of autologous peripheral blood stem cells was performed $48 \mathrm{~h}$ after the end of chemotherapy. All patients received the same supportive care. Red blood cell products and single-donor platelets were substituted to maintain a hemoglobin level above $80 \mathrm{~g} / \mathrm{l}$ and a platelet count above 10,000/ $\mu$ l. All patients were assessed by a maxillofacial surgeon or a dentist prior to high-dose chemotherapy. Pamidronate at 30,60 or $90 \mathrm{mg}$, zoledronic acid at 2, 3 or $4 \mathrm{mg}$, and ibandronate at 2, 4 or $6 \mathrm{mg}$ were administered intravenously every 4 weeks, whereas clodronate at 800 or $1600 \mathrm{mg}$ was applied orally daily. Time of exposure to bisphosphonates was defined as the time in months from the initial to the last recorded administration. Every patient who had undergone high-dose chemotherapy and was treated with bisphosphonates in our center had an oral examination at each monthly control visit. In case dental manipulations became necessary, bisphosphonates were discontinued for 1 month until wound healing was confirmed. The diagnosis of BRONJ was made according to its definition (exposed bone over a period of 8 weeks, no history of irradiation of the jaw bones, and positive medical history for bisphosphonate administration) $[18,19]$ and confirmed by an experienced maxillofacial surgeon. The treatment was performed according to the guidelines of the American Association of Oral and Maxillofacial Surgery [18]. 6 patients suffered 2 independent BRONJ events at different sites and times, partially under different bisphosphonate treatment regimens. These cases were calculated as 2 BRONJ events each.

\section{Statistical Analysis}

The patient group with BRONJ events $(\mathrm{n}=29)$ was compared to the patient group without BRONJ $(n=97)$. For statistical analyses, we used the SPSS program, the Fisher-Yates test, and the Mann-Whitney U test; p values $<0.05$ were considered as statistically significant.

\section{Results}

\section{Patient Characteristics}

The baseline characteristics of 120 multiple myeloma patients included in the analysis are listed in table 1 . The mean followup time was $62.9( \pm 38.8)$ months after the diagnosis of multiple myeloma, $46.3( \pm 30.4)$ months after the first ASCT and $35.4( \pm 27.1)$ months after the last ASCT. Of 120 patients, $23(19 \%)$ developed BRONJ. 6 patients suffered 2 BRONJ events at a different time and site, resulting in a total incidence of 29 events $(23 \%)$. The mean time between the last ASCT and BRONJ was $38.4( \pm 27.6)$ months. The majority of patients $(62 \%)$ had osteonecrosis of the mandible. There were no significant differences in patient gender, age at diagnosis of multiple myeloma, body mass index, disease stage, and pres- 
Table 1. Baseline characteristics and type of tumor treatment of 120 patients with multiple myeloma after high-dose chemotherapy and autologous stem cell transplantation

\begin{tabular}{|c|c|c|c|c|}
\hline & All events, $\mathrm{n}=120$ & BRONJ events, $\mathrm{n}=29$ & No-BRONJ events, $\mathrm{n}=97$ & $\mathrm{p}$ Values \\
\hline Current age, years & $63.5 \pm 7.1(39-77)$ & $65.9 \pm 4.9(58-73)$ & $63.0 \pm 7.4(39-77)$ & 0.04 \\
\hline Age at diagnosis of multiple myeloma, years & $58.3 \pm 6.8(37-72)$ & $57.6 \pm 6.2(45-66)$ & $58.6 \pm 6.9(37-72)$ & 0.50 \\
\hline Gender, n (F/M) & $54 / 66$ & $15 / 14$ & $34 / 54$ & 0.53 \\
\hline Body mass index & $25.7 \pm 4.0(18.8-37.9)$ & $25.5 \pm 4.5(20.1-35.4)$ & $25.8 \pm 3.8(18.8-37.9)$ & 0.52 \\
\hline $\begin{array}{l}\text { Presence of osteolyses at first diagnosis, } \\
\text { n (yes/no/unknown) }\end{array}$ & $75 / 43 / 2$ & $16 / 13 / 0$ & $61 / 34 / 2$ & 0.39 \\
\hline $\begin{array}{l}\text { Salmon and Durie stage at first diagnosis, } \\
\mathrm{n}(\mathrm{I} / \mathrm{II} / \mathrm{III} / \mathrm{unknown})\end{array}$ & $13 / 25 / 75 / 7$ & $6 / 3 / 14 / 6$ & $9 / 22 / 64 / 1$ & 0.27 \\
\hline Vitamin D substitution, $\mathrm{n}$ (yes/no) & $35 / 91$ & $6 / 23$ & $29 / 68$ & 0.48 \\
\hline Radiation therapy head/neck, n (yes/no) & $14 / 112$ & $5 / 24$ & $9 / 88$ & 0.31 \\
\hline Other radiation therapy, n (yes/no) & $55 / 71$ & $15 / 14$ & $40 / 57$ & 0.40 \\
\hline Dexamethasone therapy, n (yes/no) & $115 / 5$ & $27 / 2$ & $94 / 3$ & 0.33 \\
\hline Prednisone therapy, n (yes/no) & $38 / 82$ & $9 / 20$ & $31 / 66$ & 1.0 \\
\hline Lenalidomide therapy, $\mathrm{n}$ (yes/no) & $31 / 89$ & $13 / 16$ & $23 / 74$ & 0.10 \\
\hline Bendamustine therapy, n (yes/no) & $22 / 98$ & $7 / 22$ & $16 / 81$ & 0.41 \\
\hline Cyclophosphamide therapy, n (yes/no) & $67 / 53$ & $11 / 18$ & $57 / 43$ & 0.46 \\
\hline Thalidomide therapy, n (yes/no) & $48 / 72$ & $9 / 20$ & $41 / 56$ & 0.29 \\
\hline Bortezomib therapy, n (yes/no) & $70 / 50$ & $13 / 16$ & $59 / 38$ & 0.14 \\
\hline
\end{tabular}

ence of osteolytic lesions at first diagnosis. However, patients who developed BRONJ were significantly older at the time of data collection, reflecting a longer disease course and consequently a longer exposure time to bisphosphonates. No significant differences were detected in the use of prednisone, dexamethasone, bortezomib, thalidomide, cyclophosphamide, bendamustine and lenalidomide, the melphalan dose or radiation therapy between patients with and without subsequent BRONJ.

\section{Patient-Related Risk Factors for BRONJ}

The incidence of BRONJ was strongly associated with rheumatism: $31 \%$ of the patients with BRONJ suffered from rheumatic disease (rheumatoid arthritis or ankylosing spondylitis), compared to only $4.1 \%$ of the no-BRONJ cases ( $p=0.0001)$. Recent dental manipulations (dental extractions, root canal surgery, placement of dental implants) had occurred in 19 of 29 BRONJ events (65.5\%), compared to 20 of the no-BRONJ cases $(20.6 \%)$. There was no association of anemia, osteoporosis, diabetes mellitus, and renal failure with the development of BRONJ (fig. 1). M protein and beta-2-microglobulin were similar in patients with and without BRONJ; however, the plasma albumin concentration was higher in patients with BRONJ events $(4.7 \pm 2.7 \mathrm{~g} / \mathrm{dl}$; range $3.4-16.5 \mathrm{~g} / \mathrm{dl})$ as compared to patients without BRONJ $(3.6 \pm 0.7 \mathrm{~g} / \mathrm{dl}$; range 2.0 $4.7 \mathrm{~g} / \mathrm{dl} ; \mathrm{p}=0.01$, data not shown). Furthermore, the mean Creactive protein $(\mathrm{CRP})$ value directly preceding the $\mathrm{BRONJ}$ events was elevated to $1.6 \pm 2.7 \mathrm{mg} / \mathrm{dl}$ (normal $<0.5 \mathrm{mg} / \mathrm{dl}$ ).
Fig. 1. Comorbidities of patients with and without BRONJ. The incidence of BRONJ was associated with recent dental manipulations and rheumatism.

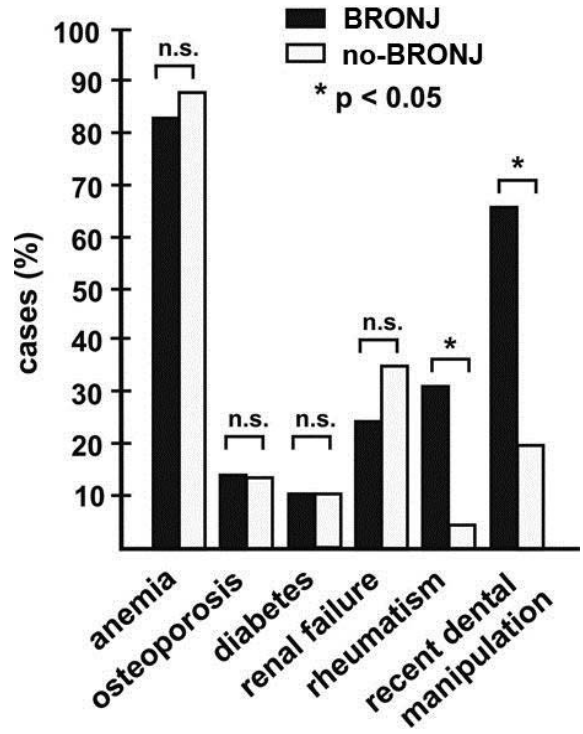

Duration and Type of Bisphosphonate Therapy and Incidence of BRONJ

The total duration of bisphosphonate treatment was significantly longer in patients who developed BRONJ (fig. 2A). Patients with BRONJ had a median duration of bisphosphonate therapy of 55 months (mean $61.3 \pm 43.0$; range 12-202 months), whereas the median duration of bisphosphonate treatment was 33.5 months (mean $42.3 \pm 32.9$; range $1-198$ months) in patients without BRONJ $(\mathrm{p}=0.014)$. The risk of 
A

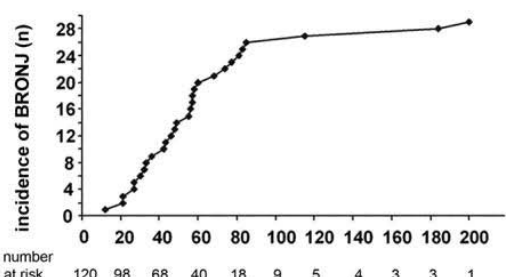

B

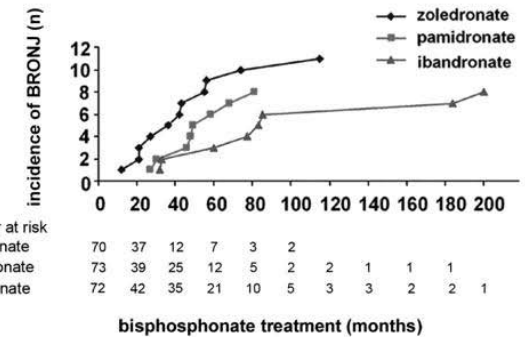

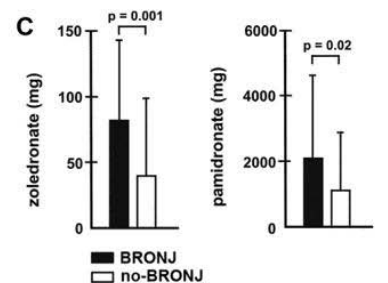

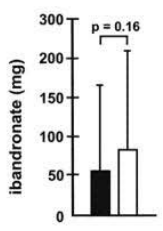

D

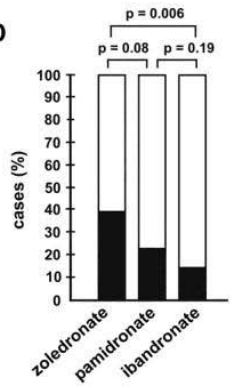

E

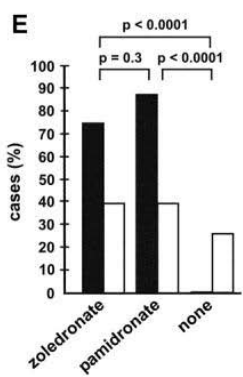

Fig. 2. (A) Cumulative incidence of BRONJ events in patients treated with bisphosphonates. (B) Cumulative incidence of BRONJ events in patients treated with zoledronate, pamidronate, and ibandronate. (C) Mean cumulative dose of zoledronate, pamidronate, and ibandronate in patients with and without BRONJ. (D) Proportions of BRONJ and no-BRONJ events under treatment with zoledronate, pamidronate, and ibandronate. (E) Percentage of BRONJ events occurring under treatment with ibandronate alone (right) or under treatment with ibandronate after pretreatment with zoledronic acid (left) or pamidronate (middle).
BRONJ was $27.6 \%$ for patients with treatment duration above the median of 33.5 months and $12.5 \%$ for patients with treatment duration below the median $(\mathrm{p}=0.018$, data not shown). Figure $2 \mathrm{~B}$ displays the BRONJ incidence according to the type of bisphosphonate. The median exposure time was 19 months for zoledronic acid (mean $21.4 \pm 15.2$ months), 21 months for pamidronate (mean $26.3 \pm 24.3$ months), 21.5 months for ibandronate (mean $32.0 \pm 32.7$ months), and 4 months for clodronate (mean $8.8 \pm 8.7$ months). Under treatment with zoledronate alone, 1 patient developed BRONJ after an exposure time of only 12 months. In contrast, no patient receiving pamidronate alone for less than 27 months developed BRONJ. 1 patient developed BRONJ after 6 months of pamidronate treatment; however, this patient had previously been treated with zoledronate for 15 months, resulting in a total exposure time of 21 months. The earliest case of BRONJ under ibandronate occurred after an exposure time of 5 months, preceded by 21 months of pamidronate treatment. The mean cumulative dose of zoledronate and pamidronate was significantly higher in the patient group that developed BRONJ. Interestingly, the ibandronate dose was non-significantly lower in the group with BRONJ (fig. 2C). There was a trend for higher BRONJ risk for patients receiving zoledronic acid than for patients treated with pamidronate. The BRONJ risk was significantly elevated for patients treated with zoledronic acid compared to patients treated with ibandronate (fig. 2D). BRONJ occurred in $39.1 \%$ of patients currently receiving zoledronic acid $(\mathrm{n}=28)$, in $22.6 \%$ of patients receiving pamidronate $(\mathrm{n}=31)$, in $14.8 \%$ of patients treated with ibandronate $(\mathrm{n}=54)$, and additionally in both patients receiving zoledronic acid and pamidronate alternatively $(n=2)$ and in 1 patient receiving clodronate $(n=1)$. The remaining patients without BRONJ had stopped the bisphosphonate treatment before data collection. Notably, no BRONJ event occurred under ibandronate alone. Patients who developed BRONJ under current treatment with iban- dronate were in $75 \%(n=6)$ of the events pretreated with zoledronic acid and in $87.5 \%(n=7)$ of the events pretreated with pamidronate (fig. 2E).

Furthermore, the incidence of BRONJ was significantly associated with the number of previous bisphosphonate rotations ( $\mathrm{p}=0.013$; fig. 3 ). Whereas in only 6 of 29 BRONJ events $(20.7 \%)$ the bisphosphonate therapy had not been changed prior to the development of BRONJ, in 8 BRONJ cases $(27.6 \%)$ the bisphosphonate therapy had been changed once, in 7 cases $(24.1 \%)$ twice, in 5 cases $(17.2 \%) 3-5$ times, and 3 patients with BRONJ (10.3\%) had undergone 10 or more rotations of the bisphosphonate therapy. Of the patients without BRONJ, 44.3\% (43 no-BRONJ events) had had no rotation of the treatment, $33.0 \%$ (32 cases) 1 rotation and $15.5 \%$ ( 15 cases) 2 rotations. Only 7 no-BRONJ cases $(7.2 \%)$ had undergone 3 or more bisphosphonate rotations.

\section{Discussion}

The present study identifies multiple myeloma patients after high-dose chemotherapy and ASCT as high-risk patients for BRONJ. Previous studies demonstrated that BRONJ is especially frequent in multiple myeloma patients with a reported incidence of $1.7-20.5 \%[21,25,26]$. The reason for this is probably the long treatment duration with high cumulative bisphosphonate doses, since myeloma patients are often affected by pathological bone fractures early in their disease course but still have a long survival compared to other patients with bone metastases. The time period of bisphosphonate treatment and the cumulative dose have emerged as valid risk factors for BRONJ [26-28]. The Mayo clinic consensus statement and the International Myeloma Working Group (IMWG) guidelines recommend reduction of bisphosphonate use to 1 or 2 years in patients reaching a plateau phase or complete response. For patients with active disease, 
therapy frequency can be decreased to every 3 months after 2 years [29, 30]. The high incidence of BRONJ events $(23 \%)$ in our study group of multiple myeloma patients after highdose chemotherapy and ASCT is possibly explained by a long disease course and a long bisphosphonate exposure (33.5 months for patients without BRONJ and 55 months for patients with BRONJ). Furthermore, the patients in our study group had all undergone aggressive high-dose chemotherapy followed by neutropenia, and had mostly been treated with multiple chemotherapy regimens during their disease course. Chemotherapy generally has immunosuppressant and antivasculogenic properties, which might be even more intense after high-dose chemotherapy. Effects of stem cell depletion induced by high-dose chemotherapy on later wound healing capacity and risk of BRONJ cannot be excluded, and aggressive or multiple chemotherapies may therefore facilitate adverse events such as BRONJ.

Other (but inconsistently described) BRONJ risk factors are anthracyclines, melphalan, thalidomide, patient age, obesity, diabetes, smoking, alcohol use, renal insufficiency, erythropoietin, and glucocorticoids [24-26, 31, 32]. In the present study, BRONJ was not related to obesity, diabetes mellitus, anemia, renal failure, the previous chemotherapy regimen, or the use of glucocorticoids. In contrast, dental extraction, mandibular tori, sharp mylohyoid ridges, and dental infections such as endodontitis, periodontitis, caries, or abscessed teeth are recognized risk factors $[15,21,26,33]$. These conditions theoretically result in local accumulation of bisphosphonates due to increased potential binding sites during bone remodeling, but also in an acidic milieu in which nitrogen-containing bisphosphonates are released into their soluble, active state $[34,35]$. Preventive measures like dental procedures proved beneficial when conducted with enough time for healing before start of the bisphosphonate therapy [36]. However, although patients treated with high-dose chemotherapy and ASCT in our center undergo dental status evaluation prior to treatment, dental manipulation due to local dental infections preceded BRONJ in two-thirds of cases, which is in line with other studies [37].

Furthermore, patients treated with zoledronic acid or pamidronate developed BRONJ more frequently and earlier compared to patients receiving ibandronate. Notably, no case of BRONJ occurred under ibandronate alone. This cannot be explained by the relative potency of the different bisphosphonates to inhibit bone remodeling alone (etidronate 1, clodronate 10 , pamidronate 100 , ibandronate 10,000 , zoledronate $100,000)[6,12,38]$, but might also be due to the different $\mathrm{pKa}$ values of the bisphosphonates, which influence their activity in different $\mathrm{pH}$ milieus as well as their release properties from the bone-bound into the soluble form [34]. Acidic milieus lead to protonated activation of nitrogen-containing groups, thereby increasing the activity of nitrogen-containing bisphosphonates. At the physiological $\mathrm{pH}$ of 7.4 , zoledronic acid is theoretically protonated to about $50 \%$, whereas ibandronate
Fig. 3. Comparison of BRONJ and no-BRONJ events in relation to the number of previous bisphosphonate rotations. Multiple rotations of the bisphosphonate treatment regimen increased the risk of BRONJ.

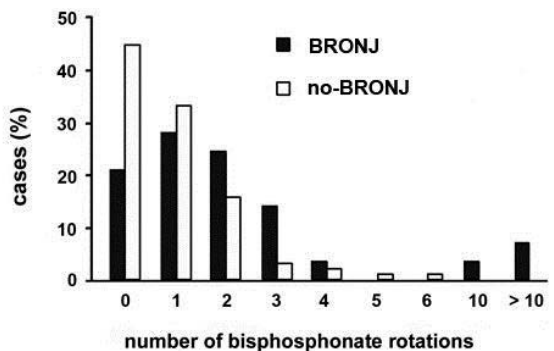

is not [39]. Inflammation generally decreases the $\mathrm{pH}$ level and, interestingly, the incidence of BRONJ in our study group was associated with an elevated CRP value and rheumatism, a condition that is accompanied by chronic inflammation, especially in the vicinity of bones. This is in line with investigations that BRONJ is often preceded by local inflammations [40, 41]. Therefore, the presence of rheumatism and especially chronic inflammatory conditions of the jaw bone should be carefully evaluated and treated prior to administration of bisphosphonates. Nevertheless, the antiresorptive effect itself seems to play a major role since denosumab, a monoclonal antibody whose efficacy in preventing skeletal-related events was demonstrated to be at least equal to zoledronate, has also shown a similar BRONJ risk [42].

Despite a higher BRONJ incidence in patients receiving zoledronic acid, it has to be taken into account that zoledronic acid has been demonstrated to be superior to the non-nitrogen-containing clodronate not only in reducing skeletal-related events, but also in decreasing overall mortality [43, 44]. This observation is consistent with preclinical data indicating that especially nitrogen-containing bisphosphonates might have inherent anticancer activities independently of their effect on bone [43, 45], which depend on inhibition of protein phenylation, a mechanism not shared by non-nitrogencontaining bisphosphonates [8, 44]. Pamidronate displayed a non-significant trend towards a lower BRONJ frequency as compared to zoledronic acid in the present study. However, it has previously been demonstrated that zoledronic acid was superior to pamidronate in preventing skeletal-related events at least in certain subsets of patients [46]. Since ibandronate, a nitrogen-containing bisphosphonate with high antiresorptive properties, is not approved for treatment of myeloma patients, data relating to ibandronate use in myeloma patients is sparse. However, a metaregression analysis has suggested a borderline significant trend for overall survival based on the bisphosphonate potency, although overall survival does not seem to be different comparing zoledronic acid, pamidronate, and ibandronate [13]. Since our study demonstrated a lower BRONJ risk associated with ibandronate in myeloma patients, further investigations concerning the efficacy and safety of ibandronate in myeloma patients are desirable. Changing the regimen from zoledronic acid to another bisphosphonate may be a theoretical option if dental procedures 
become necessary. However, in our study, patients undergoing several changes in the bisphosphonate regimen had an increased risk of BRONJ, and pretreatment with zoledronic acid or pamidronate was associated with BRONJ even after a switch to ibandronate. The higher BRONJ risk for patients having undergone bisphosphonate rotations needs further investigation. Possible explanations range from inadvertencies during changing of the regimen, such as possible overdosage because time intervals may not have been met accurately, to the different mechanisms of action of different bisphosphonate types, which may overlap due to their long binding to bone, possibly further decreasing the bone remodeling capacity [6]. Notably, in most cases, the cause for the change of bisphosphonate treatment was trivial or not apparent. However, our data demonstrates that unfounded rotations in the bisphosphonate treatment regimen should be avoided.
In conclusion, this data demonstrates that myeloma patients having undergone ASCT are at high risk for BRONJ. Treatment-related factors increasing this risk are the use of zoledronic acid, a long duration of bisphosphonate therapy, and rotations of the bisphosphonate regimen. Patient-related factors are conditions accompanied by inflammation, such as rheumatism or recent dental manipulation. Once identified, certain risk factors for BRONJ, in particular changes in the bisphosphonate regimen, can be easily avoided. For patients at high risk for BRONJ, bisphosphonates should be used with care and treatment frequency and duration should be reconsidered.

\section{Disclosure Statement}

The authors declare no competing financial interests.

\section{References}

1 Ruggiero SL: Bisphosphonate-related osteonecrosis of the jaw: an overview. Ann N Y Acad Sci 2011;1218:38-46.

2 Amin D, Cornell SA, Gustafson SK, Needle SJ, Ullrich JW, Bilder GE, Perrone MH: Bisphosphonates used for the treatment of bone disorders inhibit squalene synthase and cholesterol biosynthesis. J Lipid Res 1992;33:1657-1663.

3 Rogers MJ, Gordon S, Benford HL, Coxon FP, Luckman SP, Monkkonen J, Frith JC: Cellular and molecular mechanisms of action of bisphosphonates. Cancer 2000;88:2961-2978.

4 Walter C, Klein MO, Pabst A, Al-Nawas B, Duschner H, Ziebart T: Influence of bisphosphonates on endothelial cells, fibroblasts, and osteogenic cells. Clin Oral Investig 2010;14:35-41.

5 Otto S, Pautke C, Opelz C, Westphal I, Drosse I, Schwager J, Bauss F, Ehrenfeld M, Schieker D Osteonecrosis of the jaw: effect of bisphosphonate type, local concentration, and acidic milieu on the pathomechanism. J Oral Maxillofac Surg 2010; 68:2837-2845

6 Bartl R, Bartl C, Frisch B, Tresckow E von: Bisphosphonates in Medical Practice. Actions Side Effects - Indications - Strategies. Berlin, Springer, 2007.

7 Djulbegovic B, Wheatley K, Ross J, Clark O, Bos G, Goldschmidt H, Cremer F, Alsina M, Glasmacher A: Bisphosphonates in multiple myeloma. Cochrane Database Syst Rev 2002;(3): CD003188.

8 Guenther A, Gordon S, Tiemann M, Burger R, Bakker F, Green JR, Baum W, Roelofs AJ, Rogers MJ, Gramtzki M: The bisphosphonate zoledronic acid has antimyeloma activity in vivo by inhibition of protein prenylation. Int J Cancer 2010;126:239246.

9 Rennert G, Pinchev M, Rennert HS, Gruber SB: Use of bisphosphonates and reduced risk of colorectal cancer. J Clin Oncol 2011;29:1146-1150.

10 Rennert G, Pinchev M, Rennert HS: Use of bisphosphonates and risk of postmenopausal breast cancer. J Clin Oncol 2010;28:3577-3581.

11 Chlebowski RT, Chen Z, Cauley JA, Anderson G, Rodabough RJ, McTiernan A, Lane DS, Manson JE, Snetselaar L, Yasmeen S, O'Sullivan MJ, Safford M, Hendrix SL, Wallace RB: Oral bisphosphonate use and breast cancer incidence in postmenopausal women. J Clin Oncol 2010;28:3582-3590.

12 Corso A, Varettoni M, Zappasodi P, Klersy C, Mangiacavalli S, Pica G, Lazzarino M: A different schedule of zoledronic acid can reduce the risk of the osteonecrosis of the jaw in patients with multiple myeloma. Leukemia 2007;21:1545-1548.

13 Mhaskar R, Redzepovic J, Wheatley K, Clark OA, Miladinovic B, Glasmacher A, Kumar A, Djulbegovic B: Bisphosphonates in multiple myeloma: a network meta-analysis. Cochrane Database Syst Rev 2012;(5):CD003188.

14 Diel IJ, Bergner R, Grötz KA: Adverse effects of bisphosphonates: current issues. J Support Oncol 2007;5:475-482.

15 Marx RE: Pamidronate (aredia) and zoledronate (zometa) induced avascular necrosis of the jaws: a growing epidemic. J Oral Maxillofac Surg 2003;6: 1115-1117.

16 Migliorati CA: Bisphosphonates and oral cavity avascular bone necrosis. J Clin Oncol 2003;21: 4253-4254

17 Wang J, Goodger NM, Pogrel MA: Osteonecrosis of the jaws associated with cancer chemotherapy. J Oral Maxillofac Surg 2003;61:1104-1107.

18 American Association of Oral and Maxillofacial Surgeons: American Association of Oral and Maxillofacial Surgeons position paper on bisphosphonate-related osteonecrosis of the jaws: Advisory Task Force on Bisphosphonate-Related Ostenonecrosis of the Jaws. J Oral Maxillofac Surg 2007;65:369-376.

19 Khosla S, Burr D, Cauley J, Dempster DW, Ebeling PR, Felsenberg D, Gagel RF, Gilsanz V, Guise T, Koka S, McCauley LK, McGowan J, McKee MD, Mohla S, Pendrys DG, Raisz LG, Ruggiero SI, Shafer DM, Shum L, Silverman SI, van Poznak $\mathrm{CH}$, Watts N, Woo SB, Shane E; American Society for Bone and Mineral Research: Bisphosphonate-associated osteonecrosis of the jaw: report of a task force of the American Society for Bone and Mineral Research. J Bone Miner Res 2007;22:1479-1491.

20 Ruggiero SL, Dodson TB, Assael LA, Landesberg R, Marx RE, Mehrotra B; Task Force on Bisphosphonate-Related Osteonecrosis of the Jaws, American Association of Oral and
Maxillofacial Surgeons: American Association of Oral and Maxillofacial Surgeons position paper on bisphosphonate-related osteonecrosis of the jaw 2009 update. Aust Endod J 2009;35:119-130.

21 Walter C, Al-Nawas B, Frickhofen N, Gamm H, Beck J, Reinsch L, Blum C, Grötz KA, Wagner W: Prevalence of bisphosphonate associated osteonecrosis of the jaws in multiple myeloma patients. Head Face Med 2010;6:11.

22 Ruggiero SL, Mehrotra B, Rosenberg TJ, Engroff SL: Osteonecrosis of the jaws associated with the use of bisphosphonates: a review of 63 cases. J Oral Maxillofac Surg 2004;62:527-534.

23 Badros A, Weikel D, Salama A, Goloubeva O, Schneider A, Rapoport A, Fenton R, Gahres N, Sansville E, Ord R, Meiller T: Osteonecrosis of the jaw in multiple myeloma patients: clinical features and risk factors. J Clin Oncol 2006;24:945-952.

24 Durie BG, Katz M, Crowley J: Osteonecrosis of the jaw and bisphosphonates. N Engl J Med 2005;353:99-102.

25 Hoff AO, Toth B, Hu M, Hortobagyi GN, Gagel RF: Epidemiology and risk factors for osteonecrosis of the jaw in cancer patients. Ann N Y Acad Sci 2011;1218:47-54.

26 Pozzi S, Marcheselli R, Sacchi S, Baldini L, Angrilli F, Pennese E, Quarta G, Stelitano C, Caparotti G, Luminari S, Musto P, Natale D, Broglia C, Cuoghi A, Dini D, Di Tonno P, Leonardi G, Pianezze G, Pitini V, Polimeno G, Ponchio L, Masini L, Musso M, Spriano M, Pollastri G: Bisphosphonate-associated osteonecrosis of the jaw: a review of 35 cases and an evaluation of its frequency in multiple myeloma patients. Leuk Lymphoma 2007;48:56-64.

27 Bamias A, Kastritis E, Bamia C, Moulopoulos LA, Melakopoulos I, Bozas G, Koutsoukou V, Gika D, Anagnostopoulos A, Papadimitriou C, Terpos E, Dimopoulos MA: Osteonecrosis of the jaw in cancer after treatment with bisphosphonates: incidence and risk factors. J Clin Oncol 2005;23:8580 8587.

28 Dimopoulos MA, Kastritis E, Anagnostopoulos A, Melakopoulos I, Gika D, Moulopoulos LA, Bamia C, Terpos E, Tsionas K, Bamias A: Osteonecrosis of the jaw in patients with multiple myeloma treated with bisphosphonates: evidence 
of increased risk after treatment with zoledronic acid. Haematologica 2006; 91:968-971.

29 Lacy MQ, Dispenzieri A, Gertz MA, Greipp PR, Gollbach KL, Hayman SR, Kumar S, Lust JA, Rajkumar SV, Russell SJ, Witzig TE, Zeldenrust SR, Dingli D, Bergsagel PL, Fonseca R, Reeder CB, Stewart AK, Roy V, Dalton RJ, Carr AB, Kademani D, Keller EE, Viozzi CF, Kyle RA: Mayo clinic consensus statement for the use of bisphosphonates in multiple myeloma. Mayo Clin Proc 2006; 81:1047-1053.

30 IMWG: IMWG Guidelines for the Use of Bisphosphonates in Myeloma myeloma.gr.jp/userfiles/file/medical_info/ID317_IMWG_BP_finished_E.pdf.

31 Jadu F, Lee L, Pharoah M, Reece D, Wang L: A retrospective study assessing the incidence, risk factors and comorbidities of pamidronate-related necrosis of the jaws in multiple myeloma patients. Ann Oncol 2007;18:2015-2019.

32 Khamaisi M, Regev E, Yarom N, Avni B, Leitersdorf E, Raz I, Elad S: Possible association between diabetes and bisphosphonate-related jaw osteonecrosis. J Clin Endocrinol Metab 2007;92:1172-1175.

33 Mawardi H, Giro G, Kajiya M, Ohta K, Almazrooa S, Alshwaimi E, Woo SB, Nishimura I, Kawai T: A role of oral bacteria in bisphosphonate-induced osteonecrosis of the jaw. J Dent Res 2011;90:1339-1345.

34 Russell RG, Watts NB, Ebetino FH, Rogers MJ: Mechanisms of action of bisphosphonates: similarities and differences and their potential influence on clinical efficacy. Osteoporos Int 2008;19:733-759.

35 Sato M, Grasser W, Endo N, Akins R, Simmons H, Thompson DD, Golub E, Rodan GA: Bisphosphonate action. Alendronate localization in rat bone and effects on osteoclast ultrastructure. J Clin Invest 1991;88:2095-2105.

36 Dimopoulos MA, Kastritis E, Bamia C, Melakopoulos I, Gika D, Roussou M, Migkou M, Eleftherakis-Papaiakovou E, Christoulas D, Terpos E, Bamias A: Reduction of osteonecrosis of the jaw (ONJ) after implementation of preventive measures in patients with multiple myeloma treated with zoledronic acid. Ann Oncol 2009;20:117-120.

37 Filleul O, Crompot E, Saussez S: Bisphosphonate-induced osteonecrosis of the jaw: a review of 2,400 patient cases. J Cancer Res Clin Oncol 2010;136: 1117-1124.

38 Lin JH: Bisphosphonates: a review of their pharmacokinetic properties. Bone 1996;18:75-85.

39 Landesberg R, Cozin M, Cremers S, Woo V, Kousteni S, Sinha S, Garett-Sinha LA, Raghavan S: Inhibition of oral mucosal cell wound healing by bisphosphonates. J Oral Maxillofac Surg 2008;66:839-847.

40 Lesclous P, Abi Najm S, Carrel JP, Baroukh B, Lombardi T, Willi JP, Rizzoli R, Saffar JL, Samson I: Bisphosphonate-associated osteonecrosis of the jaw: a key role of inflammation? Bone 2009;45:843-852.

41 Otto S, Schreyer C, Hafner S, Mast G, Ehrenfeld M, Stürzenbaum S, Pautke C: Bisphosphonate-related osteonecrosis of the jaws - Characteristics, risk factors, clinical features, localization and impact on oncological treatment. J Craniomaxillofac Surg 2012;40:303-309.

42 Henry DH, Costa L, Goldwasser F, Hirsh V, Hungria V, Prausova J, Scagliotti GV, Sleeboom H, Spencer A, Vadhan-Raj S, von Moos R, Willenbacher W, Woll PJ, Wang J, Jiang Q, Jun S, Dansey R, Yeh H: Randomized, double-blind study of denosumab versus zoledronic acid in the treatment of bone metastases in patients with advanced cancer (excluding breast and prostate cancer) or multiple myeloma. J Clin Oncol 2011;29:1125-1132.

43 Morgan GJ, Davies FE, Gregory WM, Cocks K, Bell SE, Szubert AJ, NavarroCoy N, Drayson MT, Owen RG, Feyler S, Ashcroft AJ, Ross F, Byrne J, Roddie H, Rudin C, Cook G, Jackson GH, Child JA: First-line treatment with zoledronic acid as compared with clodronic acid in multiple myeloma (MRC Myeloma IX) a randomised controlled trial. National Cancer Research Institute Haematological Oncology Clinical Study Group. Lancet 2010;376:1989-1999.

44 Morgan GJ, Child JA, Gregory WM, Szubert AJ, Cocks K, Bell SE, NavarroCoy N, Drayson MT, Owen RG, Feyler S, Ashcroft AJ, Ross FM, Byrne J, Roddie H, Rudin C, Cook G, Jackson GH, Wu P, Davies FE; National Cancer Research Institute Haematological Oncology Clinical Studies Group: Effects of zoledronic acid versus clodronic acid on skeletal morbidity in patients with newly diagnosed multiple myeloma (MRC Myeloma IX): secondary outcomes from a randomised controlled trial. Lancet Oncol 2011;12:743-752.

45 Morgan GJ, Davies FE, Gregory WM, Szubert AJ, Bell SE, Drayson MT, Owen RG, Ashcroft AJ, Jackson GH, Child JA; on behalf of the National Cancer Research Institute Haematological Oncology Clinical Studies Group: Effects of induction and maintenance plus long-term bisphosphonates on bone disease in patients with multiple myeloma: the Medical Research Council Myeloma IX Trial. Blood 2012;119:5374-5383.

46 Rosen LS, Gordon DH, Dugan W Jr, Major P, Eisenberg PD, Provencher L, Kaminski M, Simeone J, Seaman J, Chen BL, Coleman RE: Zoledronic acid is superior to pamidronate for the treatment of bone metastases in breast carcinoma patients with at least one osteolytic lesion. Cancer 2004;100:36-43. 